\title{
THE EFFECT OF DIFFERENT LIGHT CURED UNIT INTENSITIES ON THE DEPTH OF POLYMERIZATION OF BULK FILL SCULPTABLE COMPOSITE RESIN RESTORATIONS
}

\author{
Alphania Esty Luthfaida*, Arlina Nurhapsari**, Helmi Fathurrahman ${ }^{* \star \star}$ \\ ${ }^{*}$ Program Pendidikan Dokter Gigi Universitas Islam Sultan Agung \\ **Departemen Konservasi Fakultas Kedokteran Gigi Universitas Islam Sultan Agung \\ ***Departemen Prosthodonsia Fakultas Kedokteran Gigi Universitas Islam Sultan Agung \\ Correspondence: arlina@unissula.ac.id
}

Keywords:

composite resin, bulk fill sculptable, depth of polymerization, vickers microhardness tester

\begin{abstract}
Background : The latest development of dental material restoration is a bulk fill sculptable composite resin. This material can be applied to a $4 \mathrm{~mm}$ cavity at once irradiation. The success of polymerization can be affected by improper irradiation. Both the physical and mechanical properties of the material also can be decreased by improper irradiation. This study aimed to determine the effect of different lightcured unit intensities on the depth of polymerization of bulk fills sculptable composite resin restorations.

Method : This research method was an experimental analytic type of post-test only control group design laboratory, consisting of 24 bulk fill sculptable composite resin with a diameter of $4 \mathrm{~mm} \times 6 \mathrm{~mm}$ thickness divided into 6 groups:A1(3M ESPE-low intensity),A2(3M ESPE-high intensity), $A 3(3 M$ ESPE-soft start intensity),B1(Ivoclar vivacity-low intensity),B2(Ivoclar vivadent-high intensity) and B3(Ivoclar vivadentsoft start intensity).

Result : The results showed a significant effect of the low, high, and soft start intensity light-cured units in the bulk fill sculptable composite resin groups by Kruskal-Wallis test $0.00(p<0.05)$.

Conclusion : The best polymerization depth of bulk fill sculptable composite resin was $3 M$ ESPE and it was affected by the high and lowintensity light-cured units.
\end{abstract}

\section{Pendahuluan}

Perkembangan terbaru resin komposit adalah resin komposit bulk fill. Jenis ini menunjukkan hasil mekanis yang lebih baik daripada resin komposit nanohybrid dan microhybrid. Resin komposit bulk fill dapat diaplikasikan pada kedalaman kavitas $4 \mathrm{~mm}$ dengan satu kali penyinaran (teknik bulk) sehingga mempercepat waktu pengaplikasian di klinik. ${ }^{1}$ Resin komposit bulk fill terdiri dari low viscosity (flowable) dan high viscosity (sculptable). Kelebihan resin komposit sculptable adalah persentase filler yang tinggi sehingga pengerutan polimerisasi rendah yang menyebabkan resin komposit bulk fill sculptable dapat bertahan lama di rongga mulut. ${ }^{2,3}$

$$
\text { Polimerisasi resin komposit }
$$

dipengaruhi oleh intensitas sinar, ketebalan bahan, jarak penyinaran, dan lama penyinaran. ${ }^{4}$ Resin komposit membutuhkan cahaya dengan panjang gelombang 460-485 $\mathrm{nm}$ dan intensitas light-emitting diode (LED) $400-500 \mathrm{~mW} / \mathrm{cm}^{2}$ dalam waktu tertentu untuk polimerisasi. ${ }^{5,6}$ Penyinaran yang tidak tepat dapat melemahkan polimerisasi resin komposit sehingga terjadi penurunan kekerasan resin dan peningkatan penyerapan air. Hal ini mengakibatkan restorasi tidak mampu 
menahan tekanan kunyah, restorasi mudah pecah dan bahan tambalan terlepas dari gigi. ${ }^{7,8}$ Keberhasilan restorasi dalam mendapatkan pancaran sinar untuk polimerisasi dipengaruhi oleh kedalaman restorasi. Pada kavitas yang dalam, sinar yang menembus ke dalam restorasi berkurang sehingga polimerisasi kurang sempurna dan nilai kekerasan resin komposit rendah.9,10 Kekerasan merupakan indikator sifat fisik suatu bahan dalam ketahanan terhadap abrasi dan juga sifat mekanik suatu bahan dalam ketahanan terhadap fraktur. ${ }^{11}$

Penelitian ini bertujuan untuk mengetahui dan memahami pengaruh intensitas light-cured unit yang berbeda terhadap kedalaman polimerisasi restorasi resin komposit bulk fill sculptable. Penelitian ini diharapkan dapat menjadi pengetahuan mengenai pengaruh intensitas light-cured unit terhadap kedalaman polimerisasi restorasi resin komposite bulk fill sculptable dan sebagai bahan masukan bagi perkembangan ilmu pengetahuan di bidang kedokteran gigi untuk penelitian lebih lanjut.

\section{METODE}

Penelitian ini telah mendapat persetujuan dari Komisi Etik Penelitian Kesehatan dan Kedokteran Fakultas Kedokteran Gigi Universitas Islam Sultan Agung Semarang No.046/B.1-KEPK/SA-FKG/X/2018. Penelitian ini dilakukan di OSCE Center Fakultas Kedokteran Gigi Universitas Islam Sultan Agung Semarang dan Laboratorium Terpadu Universitas Diponegoro Semarang.

Jenis penelitian ini adalah analitik eksperimental laboratorium rancangan post test only control group design, terdiri dari 24 spesimen resin komposit bulk fill sculptable dengan ukuran diameter $4 \mathrm{~mm} \times$ ketebalan $6 \mathrm{~mm}$ dibagi menjadi 6 kelompok yaitu A1 (3M ESPE-low intensity), A2 (3M ESPE-high intensity), A3 (3M ESPE-soft start intensity), B1 (Ivoclar vivadent-low intensity), B2 (Ivoclar vivadent-high intensity) dan B3 (Ivoclar vivadent-soft start intensity).

Penelitian ini memerlukan alat cetakan stainless steel dengan diameter $6 \mathrm{~mm} \mathrm{x}$ ketinggian 8mm (Standar ISO 4049) dan LED Bluephase dengan tiga intensitas yaitu low (650 $\left.\mathrm{mW} / \mathrm{cm}^{2}\right)$, high $\left(1200 \mathrm{~mW} / \mathrm{cm}^{2}\right)$ dan soft start (650-1200 $\left.\mathrm{mW} / \mathrm{cm}^{2}\right)$. Bahan yang dipakai adalah resin komposit bulk fill sculptable $3 \mathrm{M}$ ESPE, resin komposit bulk fill sculptable Ivoclar-vivadent dan saliva buatan.

Bahan resin komposit bulk fill sculptable diletakkan kedalam cetakan stainless steel dengan ukuran diameter $4 \mathrm{~mm} \times$ ketinggian $6 \mathrm{~mm}$. Sebelum dipolimerisasi dengan lightcured unit, LED bluephase diperiksa intensitasnya terlebih dahulu dengan menggunakan radiometer (standar ISO 10650). Pada permukaan atas sampel resin komposit diletakkan mylar strip kemudian di polimerisasikan menggunakan light-cured unit. Waktu penyinaran masing-masing kelompok berdasarkan petunjuk pabrikan, kelompok A1 (3M ESPE-low intensity) adalah 30 detik, kelompok A2 (3M ESPE-high intensity) dan A3 (3M ESPE-soft start intensity) 20 detik. Sedangkan pada kelompok B1 (Ivoclar vivadent-low intensity) adalah 20 detik, B2 (Ivoclar vivadent-high intensity) 10 detik dan B3 (Ivoclar vivadent-soft start intensity) 15 detik. Setelah terpolimerisasi, sampel dikeluarkan dari cetakan dan di inkubasi di dalam saliva buatan selama 24 jam dengan suhu $37^{\circ} \mathrm{C}$. 
Setelah di inkubasi, dilakukan pengukuran kedalaman polimerisasi dengan vickers hardness tester (VHN) dari kedalaman 0,5 mm dengan tiga kali indentasi sampai kedalaman 6 $\mathrm{mm}$. Hasil kekerasan yang diperoleh secara digital kemudian dicatat untuk dianalisa.

Analisis hasil penelitian ini dilakukan uji normalitas dengan shapiro-wilk dan uji homogenitas dengan uji levene. Hasil data yang didapat adalah terdistribusi normal dan tidak homogen sehingga dilanjutkan dengan analisa uji Kruskal-Wallis dan uji MannWhitney.

\section{HASIL PENELITIAN}

Hasil uji kekerasan terhadap kedalaman polimerisasi resin komposit bulk fill scultpable menunjukan nilai rata-rata kedalaman polimerisasi 6 kelompok sebagai berikut.

\section{Kedalaman Polimerisasi RK BF Sculptable Oleh Tiga Intensitas}

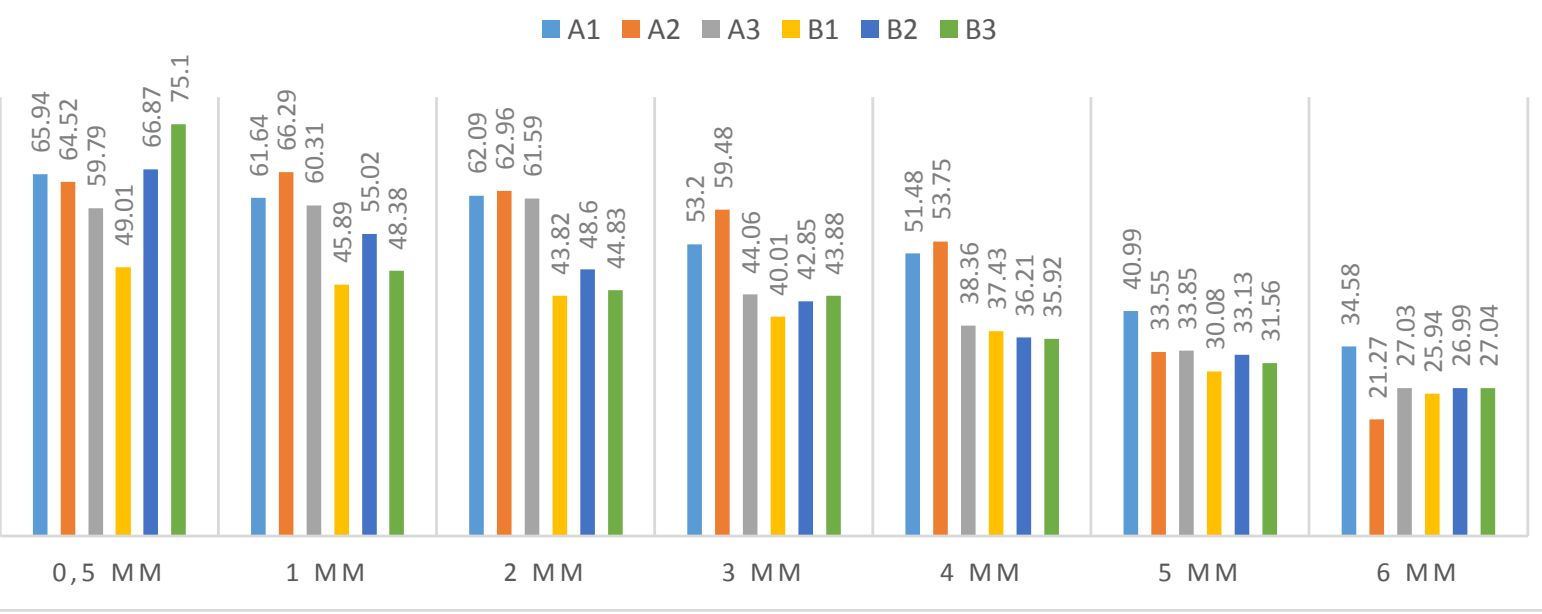

Gambar 1 Nilai kedalaman polimerisasi resin komposit bulk fill scultpable pada kelompok A1 (3M ESPE-low intensity), A2 (3M ESPE-high intensity), A3 (3M ESPE-soft start intensity), B1 (Ivoclar vivadent-low intensity), B2 (Ivoclar vivadent-high intensity) dan B3 (Ivoclar vivadent-soft start intensity).

Tabel 1. 1. Persentase kedalaman polimerisasi resin komposit bulkfill sculptable

\begin{tabular}{ccccccc}
\hline \multirow{2}{*}{$\begin{array}{c}\text { Kedalaman } \\
\text { Polimerisasi }\end{array}$} & A1 & A2 & A3 & B1 & B2 & B3 \\
\cline { 2 - 7 } & 100 & 100 & 100 & 75 & 100 & 100 \\
\hline $0,5 \mathrm{~mm}$ & 93 & 100 & 100 & 70 & 82 & 64 \\
\hline $1 \mathrm{~mm}$ & 94 & 97 & 97 & 67 & 70 & 60 \\
\hline $2 \mathrm{~mm}$ & 80 & 92 & 89 & 62 & 65 & 59 \\
\hline $3 \mathrm{~mm}$ & 78 & 92 & 62 & 58 & 54 & 57 \\
\hline $4 \mathrm{~mm}$ & 62 & 52 & 54 & 47 & 48 & 42 \\
\hline $5 \mathrm{~mm}$ & 53 & 32 & 42 & 39 & 40 & 35 \\
\hline $6 \mathrm{~mm}$ & & & & & &
\end{tabular}


Kedalaman polimerisasi resin komposit bulkfill sculptable 3M ESPE lebih tinggi dibandingkan Ivoclar-vivadent. Persentase VHN maksimal terjadi pada kelompok A2 yang dapat mempertahankan kedalaman polimerisasi terbaik sampai $4 \mathrm{~mm}$ (>80\%). Keompok B1 menunjukkan nilai persentase terendah ( $<80 \%)$. Kelompok A1 dan A2 dapat mempertahankan kedalaman polimerisasi sampai $3 \mathrm{~mm}$, Kelompok B2 hanya kedalaman $2 \mathrm{~mm}$ sedangkan B3 pada kedalaman 0,5 mm.
Data hasil penelitian kemudian dilakukan uji normalitas dan homogenitas, didapatkan hasil data terdistribusi normal dan tidak homogen sehingga dilakukan uji alternatif Kruskal-Wallis. Hasil analisis data statistik Kruskal-Wallis diperoleh nilai kemaknaan penelitan kurang dari 0,05. Hal ini menunjukkan adanya perbedaan berrmakna kedalaman polimerisasi resin komposit bulk fill sculptable antara kelompok low, high, dan soft start intensity LCU.

Tabel 1. 2. Hasil uji Mann-Whitney

\begin{tabular}{|c|c|c|c|c|c|c|c|}
\hline \multirow{2}{*}{ Kelompok } & \multicolumn{7}{|c|}{ Sig. pada kedalaman polimerisasi } \\
\hline & $0,5 \mathrm{~mm}$ & $1 \mathrm{~mm}$ & $2 \mathrm{~mm}$ & $3 \mathrm{~mm}$ & $4 \mathrm{~mm}$ & $5 \mathrm{~mm}$ & $6 \mathrm{~mm}$ \\
\hline $\mathrm{A} 1-\mathrm{A} 2$ & 0,02 & 0,02 & 0,02 & 0,02 & 0,02 & 0,02 & 0,02 \\
\hline $\mathrm{A} 1-\mathrm{A} 3$ & 0,02 & 0,02 & $0,66^{\mathrm{b}}$ & 0,01 & 0,02 & 0,02 & 0,02 \\
\hline $\mathrm{A} 1-\mathrm{B} 1$ & 0,02 & 0,01 & 0,02 & 0,02 & 0,02 & 0,02 & 0,02 \\
\hline $\mathrm{A} 1-\mathrm{B} 2$ & 0,01 & 0,02 & 0,02 & 0,02 & 0,02 & 0,02 & 0,02 \\
\hline $\mathrm{A} 1-\mathrm{B} 3$ & 0,02 & 0,02 & 0,02 & 0,02 & 0,02 & 0,02 & 0,02 \\
\hline $\mathrm{A} 2-\mathrm{A} 3$ & 0,02 & 0,02 & 0,02 & 0,02 & 0,02 & $0,77^{\mathrm{b}}$ & 0,02 \\
\hline $\mathrm{A} 2-\mathrm{B} 1$ & 0,02 & 0,02 & 0,02 & 0,02 & 0,02 & 0,02 & 0,02 \\
\hline A2 - B2 & 0,01 & 0,02 & 0,02 & 0,02 & 0,02 & $0,46^{b}$ & 0,02 \\
\hline $\mathrm{A} 2-\mathrm{B} 3$ & 0,02 & 0,02 & 0,02 & 0,02 & 0,02 & $0,14^{\mathrm{b}}$ & 0,02 \\
\hline$A 3-B 1$ & 0,02 & 0,02 & 0,02 & 0,02 & 0,02 & 0,02 & 0,02 \\
\hline $\mathrm{A} 3-\mathrm{B} 2$ & 0,02 & 0,02 & 0,02 & 0,02 & 0,02 & $0,38^{b}$ & $0,77^{b}$ \\
\hline A3 - B3 & 0,02 & 0,02 & 0,02 & $0,24^{b}$ & 0,02 & 0,02 & $1,00^{b}$ \\
\hline $\mathrm{B} 1-\mathrm{B} 2$ & 0,02 & 0,02 & 0,02 & 0,02 & 0,02 & 0,02 & 0,02 \\
\hline B1 - B3 & 0,02 & 0,02 & 0,02 & 0,02 & 0,02 & 0,02 & 0,02 \\
\hline $\mathrm{B} 2-\mathrm{B} 3$ & 0,02 & 0,02 & 0,02 & 0,04 & $0,46^{\mathrm{b}}$ & 0,02 & $0,88^{b}$ \\
\hline
\end{tabular}

Pada uji Mann-Whitney, secara keseluruhan hampir setiap kelompok sampel menunjukkan terdapat perbedaan yang bermakna $(p<0,05)$ kedalaman polimerisasi kecuali pada kedalaman $2 \mathrm{~mm}$ (A1-A3), $3 \mathrm{~mm}$ (A3-B3), 4 $\mathrm{mm}$ (B2-B3), $5 \mathrm{~mm}$ (A2 - A3,B2,B3, dan A3-B2), dan $6 \mathrm{~mm}$ (A3 - B2,B3, dan B2-B3). 


\section{PEMBAHASAN}

Hasil analisa statistik didapatkan adanya perbedaan bermakna antara masing-masing kelompok perlakuan dengan tiga intensitas LCU yaitu low, high, dan soft start. Perbedaan kedalaman polimerisasi ini dipengaruhi oleh teknik penyinaran, intensitas sinar, ketebalan bahan restorasi, dan waktu penyinaran. ${ }^{5}$

Kedalaman polimerisasi terbaik terdapat pada kelompok resin komposit bulk fill sculptable 3M ESPE dengan intensitas high LCU. Penggunaan LED high intensity menyebabkan resin lebih mudah terpolimerisasi sehingga cepat berubah menjadi padat dan meningkatkan nilai kekerasaan. ${ }^{12}$ Kandungan bahan yang terdapat pada resin komposit bulk fill sculptable 3M ESPE juga mengakibatkan nilai kekerasan kelompok ini lebih tinggi dengan kelompok lainnya. Matriks resin yang terdapat pada bahan ini adalah BisGMA, UDMA dan TEGDMA mengakibatkan ikatan polimernya kuat karena derajat konversi tinggi. ${ }^{13} \mathrm{AFM}$ yang ditambahkan oleh produsen diindikasikan sebagai penguat terjadinya polimerisasi. ${ }^{14}$ Struktur filler yang lebih kecil $(\mathrm{nm})$ serta volume filler yang lebih besar memungkinan terjadinya kepadatan tumpatan karena partikel filler tersebut mengisi jarak antarpolimer yang terbentuk dan mengurangi ruang kosong antarpolimer sehingga hasil akhir polimerisasi baik.

\section{KESIMPULAN}

Terdapat pengaruh intensitas light cured unit yang berbeda terhadap kedalaman polimerisasi resin komposit bulk fill sculptable. Penggunaan low dan high-intensity pada kelompok resin komposit bulk fill sculptable menunjukkan kedalaman polimerisasi terbaik dibandingkan dengan kelompok lainnya.

\section{UCAPAN TERIMAKASIH}

Terimakasih kepada Fakultas Kedokteran Gigi Unissula yang telah memberikan kesempatan, mendukung serta memfasilitasi penelitian ini. Terimakasih kepada dosen pembimbing saya yang telah memberikan arahan serta masukan dalam penelitian ini. Terimakasih kepada keluarga, sahabat, dan teman-teman yang telah mendukung penulis selama penelitian.

\section{DAFTAR PUSTAKA}

1. Llie N, Bucuta S, Draenert, M. Bulk-fill Resin-based Composites: An In Vitro Assessment of Their Mechanical Performance. Operative Dentistry. 2013 Apr 38(6):618-625

2. Ahmad I. Deep resins, white fillings: a new technique for composite restoration. J Cosmet Dent. 2013. 12-18.

3. Nurhapsari A. Perbandingan Kebocoran Tepi Antara Restorasi Resin Komposit Tipe Bulk-Fill dan Tipe Packable dengan Penggunaan Sistem Adhesif Total Etch dan Self Etch. ODONTO Dental Journal. 2016 July 3(1): 8-13.

4. Sakaguchi RL. Powers JM. Craig's Restorative Dental Materials. Ed ke-13. Philadelphia: Mosby Elsevier; 2011.

5. Susanto AA. Pengaruh ketebalan bahan dan lamanya waktu penyinaran terhadap kekerasan permukaan resin komposit sinar. Dental Journal. 2005 Jan 38(1):3235

6. Alkhudhairy FI. The effect of curing intensity on mechanical properties of different bulk-fill composite resins. Clinical, Cosmetic and Investigational Dentistry. 2017 Feb 9:1-6.

7. Paula $A B$, Tango $R N$, Sinhoreti MAC, Alves MC, PuppinRontani RM. Effect of thickness of indirect restoration and distance from the light-curing unit tip on the hardness of a dual-cured resin cement. Brazilian Dental Journal. 2010 Apr 21(2):117-122. 
8. Allorerung J, Anindita PS, Gunawan PN. Uji Kekerasan Resin Komposit Aktivasi Sinar dengan Berbagai Jarak Penyinaran. Jurnal e-GIGI(eG). 2015 July 3(2): 0-4.

9. Alrahlah A, Silikas N, Watts DC. Post-sure depth of bulk fill dental resin composites. Dent Mater. 2014 Feb 30(2):149-54.

10. Ratih DN dan Novitasari A. Kekerasan mikro resin komposit packable dan bulk fill dengan kedalaman kavitas berbeda. Majalah Kedokteran Gigi Indonesia. 2017 Aug 3(2):6-82.

11. Anusavice KJ. Philips' Science of Dental Material. Ed ke-10. EGC:Jakarta; 2004.

12. Fitriyani S, Herda E, Haryono A. Pengaruh Intensitas Cahaya Tehadap Derajat
Konversi Komposit Nano Partikel. Indonesian Journal of Dentistry. 2007 14(2): 46-152.

13. Nurhapsari A, dan Kusuma, ARP. Penyerapan air dan kelarutan resin komposit tipe microhybrid, nanohybrid, packable dalam cairan asam. ODONTO Dental Journal. 2018 July 5(1):67-75.

14. Filtek ${ }^{\mathrm{TM}}$ Bulk-fill Posterior Restorative Technical Product Profile [Internet]. [diakses 5 April 2018] terdapat di:http://multimedia.3m.com $/ \mathrm{mws} / \mathrm{media} / 9$ 766340/filtek-bulk-fill-posteriorrestorative-technical-product-profile.pdf. 